\title{
Risk Factors Associated with Falls among Nursing Home Residents: A Case-Control Study
}

\author{
Cristina Imaginário $^{a}$ Teresa Martins $^{\mathrm{b}}$ Fátima Araújo ${ }^{\mathrm{b}}$ Magda Rocha ${ }^{\mathrm{c}}$ \\ Paulo Puga Machadob \\ a UTAD, Vila Real, Portugal; b Escola Superior de Enfermagem do Porto, CINTESIS, Porto, Portugal; \\ ${ }^{c}$ CINTESIS, Porto, Portugal
}

\section{Keywords}

Falls $\cdot$ Nursing home $\cdot$ Risk assessment

\begin{abstract}
Introduction: To identify factors predictive of falls and enable appropriate management of fall risk it is necessary to understand the behaviour and health conditions of older adults living in nursing homes. Objective: This study had two main objectives. The first was to find significant predictors for falls in older adults living in nursing homes. The second main goal was to build a predictive model to find the best predictors for falls. Methods: Out of 56 nursing homes with the same legal statute, 25 agreed to participate. The sample was randomly selected and only the independent or slight/ moderately dependent participants were included in the study ( $n=325$ ). Results: There was a mean of $1.47 \pm 0.99$ falls (range from 1 to 7) per resident in nursing homes. By using the $t$ test and odds ratio analysis, ten factors related to falls were identified. Through the binary logistic regression, a model was tested identifying four robust predictors: static balance, resorting to emergency services, polypharmacy, and an independent self-care profile. Conclusions: The present study replicated the main results of contemporary research on the risk factors of falls. More importantly, it sug-
\end{abstract}

gests that the self-care profile model should be taken into account in future studies and early interventions. It is crucial to implement preventive measures consistent with safer environments and to establish an individual plan for integrated activities according to older adults' health needs.

(c) 2021 The Author(s). Published by S. Karger AG, Basel on behalf of NOVA National School of Public Health

\section{Fatores de risco associados a quedas entre residentes de estruturas residenciais para pessoas idosas: um estudo de caso-controle}

\section{Palavras Chave}

Quedas · Estruturas residenciais para idosos · Avaliação de risco

\section{Resumo}

Introdução: Para identificar os fatores preditivos de quedas e permitir a gestão adequada do seu risco, é necessário compreender o comportamento e as condições clínicas dos idosos. Objetivos: Este estudo teve dois objetivos principais. O primeiro foi encontrar preditores para quedas em idosos que vivem em estruturas residenciais (c) 2021 The Author(s). Published by S. Karger AG, Basel on behalf of NOVA National School of Public Health

This is an Open Access article licensed under the Creative Commons Attribution-NonCommercial-4.0 International License (CC BY-NC) (http://www.karger.com/Services/OpenAccessLicense), applicable to the online version of the article only. Usage and distribution for commercial purposes requires written permission.
Correspondence to:

Teresa Martins, teresam@esenf.pt 
para idosos. O segundo objetivo principal foi construir um modelo preditivo para encontrar os melhores preditores de quedas. Métodos: De um total de 56 estruturas residenciais para idosos contactados, com o mesmo enquadramento legal, 25 aceitaram participar. A amostra foi selecionada aleatoriamente e apenas os participantes independentes ou com um compromisso leve/moderado foram incluídos no estudo ( $n=325)$. Resultados: Registou-se uma média de $1.47 \pm 0.99$ quedas (variando entre 1 a 7) por participante. Por meio do teste t e da análise de odds ratio, foram identificados dez fatores relacionados com as quedas. Através da regressão logística binária, foi testado um modelo identificando quatro preditores robustos: equilíbrio estatístico, recurso a serviços de emergência, polifarmácia e perfil de autocuidado independente. Conclusões: O presente estudo replicou os principais resultados de pesquisas contemporâneas sobre os fatores de risco para quedas. Mais importante ain$\mathrm{da}$, sugere que o modelo de perfil de autocuidado deve ser levado em consideração em estudos futuros e intervenções precoces. É fundamental implementar medidas preventivas condizentes com ambientes mais seguros e estabelecer um plano individual de atividades integradas de acordo com as necessidades de saúde dos idosos.

๑ 2021 The Author(s) Published by S. Karger AG, Basel on behalf of NOVA National School of Public Health

\section{Introduction}

About 1,800 older adults living in nursing homes die each year from fall-related injuries. Those who survive frequently sustain hip fractures and head injuries that result in permanent disabilities and reduced quality of life [1]. Moreover, the literature suggests that $20-30 \%$ of falls in long-term care facilities are preventable [2]. The institutionalised older adults show a higher risk of falls, not only due to having to adapt to a new environment but also due to restrictions to their routines $[3,4]$. They tend to be mostly older adults with several health issues, which makes them more vulnerable and fragile $[4,5]$. Fragility is commonly associated with ageing and falls [6-8]. According to the World Health Organisation (WHO), 30$50 \%$ of institutionalised older adults fall every year and $40 \%$ of them experience recurring falls [9]. The higher the commitment to carrying out their basic activities of daily life (BADL), the higher the risk of falls $[8,10,11]$, with functionally impaired older adults having five times more risk of falling than those who are independent [12]. A reduction in their capacity to carry out the activities of dai-

Risk Factors Associated with Falls among Nursing Home Residents ly living can lead to a decrease in their physical strength due to a lack of muscle activity $[11,13]$. In addition, posture control and maintaining balance, mostly associated with cognitive changes in ageing, are also associated with falls [14-19]. Paresthesia, due to peripheral neuropathy or sensorial loss, produces several sudden sensations, which in turn can decrease motor and spatial perceptions, which ultimately results in falls $[20,21]$. The overactive bladder is a strong predictor of falls in older adults, which is associated with the urgency of having to get to the restroom [4, 22-24]. Insomnia as well as the medication prescribed for sleep disorders are also associated with a risk of falls $[24,25]$. Poor sleep quality can cause a decrease in physical ability among older adults [25]. Dyspnea represents a common health condition among older adults, which has multiple causes inducing several of the falls reported in the literature [26]. Due to the high rate of morbidity, as well as chronic degenerative diseases and disabilities, older adults resort to health services more often when compared to mature adults, especially to emergency services $[27,28]$. Also due to multiple diseases, older adults tend to take a lot of medicines, with polypharmacy being one of the severe problems related to falls [4, $8,23,24,29,30]$.

Theoretically, the self-care profile model might also play an important role in the study of falls recurrence because it represents an individual lifestyle, framed by values and beliefs learnt from the specific culture and the life experiences of each person. These are associated with experiences, which tend to affect the personal vision of health and illness, as well as the role of each typology, more or less proactive, with more or less risk, in the participation of defining a medical treatment plan and carrying out their self-care activities [31]. Self-care behaviours among older adults are seen as actions that aim to maintain or reestablish health through activities of daily life (ADL). According to Backman and Hentinen [32] there are four profiles: responsible, formally guided, independent, and abandoned. The responsible profile tends to continue living as an active agent, enjoying social activities, having positive relationships with family and friends, trusting the future, and waiting, as well as accepting support from others when needed [32]. The formally guided profile usually shows a life history characterised by dependence on others. This profile behaves with an uncritical attitude; therefore, whatever the staff tell them to do is scrupulously accomplished, consequently diminishing the risk of falls, but often at a cognitive cost (making decisions, critical thinking, etc.) [32]. The independent profile tends to manage its health-illness process by making decisions 
mainly based on their perceptions and beliefs about health, and inclusively going against the therapeutic recommendations of health care workers. They try to find answers to their problems on their own, basing their answers on experiences and personal beliefs developed throughout their lives. They display attitudes of denial towards ageing, not verbalising any signs or symptoms of disease [32]. Finally, the abandoned profile is characterised by personal representations of impotence and lack of responsibility. They do not care about themselves, displaying an incapacity to manage their activities of daily living. They also display a negative attitude towards ageing, with personal characterisations of incapacity, resulting in feelings of impotence and abandonment. It is characterised by the desire to give up and to interiorise a feeling of losing control of their personal lives, a product of their perception of physical and cognitive impairment [32]. Taking into account the characteristics of each profile, it is believed that there are profiles that are associated with an increased risk of falls, either due to the sense of total autonomy that no longer exists, or due to personal discouragement, or even due to a total absence of autonomy. These features give rise to the perception that one is capable of everything, to the perception that nothing is worthwhile, or that one is incapable of doing something without the opinion of others. These are the least adaptive profiles, which can increase falls, either due to the lack of promotion of ADLs or the lack of risk limits. The responsible profile is the most adaptive and productive way to maintain a high quality of life, for as long as possible [32].

This study was motivated to contribute to the broadening of the field of knowledge regarding the risks of falls in older adults, to consider forms of intervention to minimise the number of falls in these populations. The study aimed to identify the factors associated with falls in older adults living in nursing homes, through previously studied variables, introducing self-care profiles as a new predictor of falls. Two main objectives were formulated, based on the aforementioned context and considering that the present study's main focus was on older adults living in nursing homes who still have a certain degree of independence and could benefit from preventive measures. The first main goal was to determine the significant predictors for falls in older adults living in nursing homes among the continuous and dichotomous variables in our database. The corresponding hypothesis was that among the tested predictors, the self-care profiles would be among the significant ones. The second main goal was to build a predictive model to find the best predictors among the significant ones.

\section{Materials and Methods}

A case-control design study was conducted with a retrospective approach and an analytic proposal with older adults with some level of independence, living in nursing homes. Those with a record of falls were considered as cases.

A total of 56 nursing homes were contacted and invited by email to participate in this study in a region in the North of Portugal, of which 25 chose to participate (with a total of 1,586 residents). All 56 institutions were from the same geographical area, and share the same objective features, i.e., they are part of a national registry of institutions, financially supported by the Portuguese government and with the same legal statute. The goal of collecting a representative sample was achieved by randomly selecting $30 \%$ of the older adults $(n=475)$, who were living at each one of the nursing homes and fulfilled the inclusion criteria. The $30 \%$ percentage was re-established whenever informed consent was not granted by the respondent or by their legal representative. In that case, another possible participant was randomly selected from the pool of those who fulfilled the ethical and inclusion criteria. As part of the inclusion criteria, the participants had to voluntarily agree to participate, and whenever this approval depended on a legal representative, only with their explicit consent was the older adult included in the sample. Finally, the older adults must have been institutionalised for at least 1 year.

The factors associated with falls differ between dependent people from those with independence or with slight or moderate loss of independence. People who are completely dependent tend to fall especially because their required care or resources are not guaranteed, while people with independence or who are slightly or moderately compromised tend to fall due to factors more related to their health condition or situation, especially when exposed to unsafe environments [33]. The study focused primarily on the latter group, i.e., to analyse the factors that can be targeted for future interventions in nursing homes. For this reason, there was an exclusion criterion in the present study, which was the elimination of the dependent older adults, using the Barthel index cut-off value (Barthel index $\leq 9 ; n=150$ ). Thus, only the older adults with or without a record of falls were included, although they could still be independent or with a slight/moderate dependence for BADL.

Ethical principles were followed with the right to anonymity, privacy, and data confidentiality (when collecting and treating the data) [34]. The free and informed consent from the participants was gathered according to the ethical principles of research in human sciences [34]. The ethics commission of Abel Salazar Institute of Biomedical Sciences of the University of Porto, under registration number $166 / 2016$, approved this research project.

The sample in this study included 325 participants $\left(n_{\text {male }}=115\right.$; $\left.n_{\text {female }}=210\right)$, with ages between 65 and 99 years $($ mean $=83.55$, $\mathrm{SD}=7.02)$. In relation to marital status, $16 \%(n=52)$ were married, $23.1 \%(n=75)$ were single, $59.4 \%(n=193)$ were widowers or widows, and the remaining $1.5 \%(n=5)$ were divorced. Most participants had a low level of education, with $50.9 \%$ being illiterate.

Sociodemographic variables (age, gender, scholarship, etc.) and clinical data (overactive bladder, respiratory function, sensorial function, and sleep) were obtained from clinical records.

There were clinical data related to falls that occurred in the previous year, which was collected by consulting the medical records of each participant. This included numbers of falls and their consequences, number of prescribed medicines, clinical conditions, 
and records of resorting to emergency services. The latter had information that was not related only to falls but also to other acute disease situations and decompensation. The clinical conditions gathered were: urinary incontinence, changes in respiratory function/dyspnea, vision and hearing problems, and sleep disorders. When a diagnosis of urinary incontinence was found, it was confirmed with nursing home clinical staff whether it was an overactive bladder, stress incontinence, or total incontinency. Also, changes in respiratory function/dyspnea were only considered if they were dyspnea related to activities or dyspnea at rest.

To complete the data gathered retrospectively, a member of the research team at the beginning of the study carried out a functional (Barthel index; Self-Care Evaluation Form [SCEF], and Tinetti Balance Test), cognitive (Mini-Mental State Examination; MMSE), and behaviour assessment (self-care of home-dwelling elderly; SCHDE) of all the participants. Because of the fragility of the participants and their risk of falls (only $42.8 \%$ of the elderly had no difficulty in walking) the gait and muscle strength were not assessed.

The Barthel index validated for the Portuguese population [35] was used to meet the inclusion and exclusion criteria for independence, with those older adults who had a score equal to or below 9 being excluded because it indicated a degree of total dependence in their BADL. The Portuguese version of the MMSE was used to assess the cognitive state of the participants [36]. The MMSE is considered an appropriate instrument for a brief cognitive evaluation of populations with low levels of education, at advanced ages. The normative values used for the Portuguese population were adjusted to the level of education [37]. The MMSE is comprised of 30 questions, with 1 point being attributed for each correct answer. The proposed cut-off values for the cognitive impairment were the following: 22 points for participants with $0-2$ years of schooling; 24 points for those with 3-6 years of schooling, and 27 points for participants with more than 7 years of schooling [37].

The dependence related to self-care activities was assessed by the SCEF [38]. The domains of the SCEF (walking, transferring, turning, lifting, using the toilet, feeding, getting ready, dressing, bathing, taking medication, and recreational activities) are structured according to the International Classification for Nursing Practice (ICNP, 2006) [39] and the items of each domain are based on the Nursing Outcomes Classification (NOC) [40]. The study of the instrument metric properties showed a high fidelity rate [32, 41]. Higher values are indicative of a higher level of Independence.

The SCHDE was also used [32]. The 42 items of the SCHDE describe four profiles of self-care: responsible, formally guided, independent, and abandoned. Each participant obtained a score for each self-care profile. To input the variable into the regression model, it was dichotomised, and the cut-off off point was established at the 75th percentile.

Static balance was assessed using a Portuguese version of the Tinetti Balance Test [42]. Through nine items (two items scored from $0-1$ and seven from $0-2$ ) a maximum score of 16 can be obtained, indicative of balance without changes [42]. In addition to this test, the presence or not of paresthesia was determined for each subject.

All the data was gathered through interviews, in the presence of a staff member of the institution. This option was necessary due to the low literacy levels of several participants, as well as visual or fine motor skills impairments, which prevented the participants from completing the self-reported questionnaires. Another issue

Risk Factors Associated with Falls among Nursing Home Residents that requires clarification is that the SCHDE was only applied to those who presented a verbal response not associated with cognitive impairment or confusion.

Statistical analyses were performed using SPSS for Windows, version 26. The study of the differences in the averages between the older adults who suffered falls and those who did not was carried out using the $t$ test for independent samples. The procedure was computed mainly to identify possible risk factors to be introduced in the final model. The analysis of the risk factors between two dichotomous variables was performed through an odds ratio analysis. This measure, used in retrospective studies, evaluates the relationship between a variable (considered a risk factor) that precedes another one (event exposure). With the results of the two explorative analyses of the variables with a statistically significant association to the risk of falls, a binary logistic regression was used to estimate the probability of experiencing falls. The estimation model (likelihood ratio) was determined by the stepwise forward method, where the predictive variables are identified sequentially according to their discriminatory power, with the first variable being the one that best explains the model. To determine the significance of the logistic coefficient, the Wald and the Hosmer-Lemeshow goodness-of-fit tests were used to verify how well the model accounted for the specific outcomes.

The model's discriminative power was estimated by the receiver-operating characteristic (ROC) area under the curve (AUC) analysis. An optimal cut-off value for adequate sensitivity and specificity was also implemented based on the Youden index [43]. AUCs can range between 0 and 1 ; an AUC $<0.5$ indicates that the model performs worse than chance, whereas an AUC of 1 indicates perfect discrimination. AUCs $\geq 0.7$ and $>0.9$ are considered acceptable and high, respectively [44]. In constructing the ROC curve, sensitivity is plotted against 1 - specificity. The optimal score is the cut-off point with the highest true positive and lowest false positive values. To select this cut-off score, the Youden index was calculated as sensitivity + specificity -1 . The cut-off score associated with the highest Youden index indicated the optimal score to identify those with a higher risk of a fall [43].

\section{Results}

Based on the clinical records of the participants, $43.4 \%$ ( $n=141)$ had suffered at least one fall in the previous year, and $56.6 \%(n=184)$ had not. A mean of $1.47 \pm 0.99$ falls (range from 1 to 7 ) per resident was calculated. The main locations where falls took place were: in the bedroom, $23.4 \%(n=33)$; in the bathroom, $21.3 \%(n=30)$; in the hallway, $13.5 \%(n=19)$, and outdoors, $22.7 \%(n=32)$. The time of day when the falls occurred was as follows: the majority occurred in the morning (44.3\%), 32.9\% in the afternoon, and $22.8 \%$ at night. The consequences of the falls were as follows: $71.6 \%(n=101)$ suffered lesions, with $59.6 \%(n=84)$ of these needing health care assistance. Situations that caused the falls included slipping, tripping, or stumbling $(64.5 \% ; n=91)$, with other recurring falls resulting from falling from a chair $(9.2 \% ; n=13)$, 
Table 1. Independent sample $t$ test for differences between the averages of risk variables among older adults who fell and older adults who did not fall $(n=325)$

\begin{tabular}{llll}
\hline & Fall & No fall & $p$ \\
\hline Age & $83.92(7.09)$ & $83.28(6.98)$ & $\mathrm{ns}$ \\
Time in the institution, months & $57.69(61.91)$ & $58.13(62.22)$ & $\mathrm{ns}$ \\
MMSE & $18.55(5.51)$ & $17.74(6.68)$ & $\mathrm{ns}$ \\
Barthel index & $16.85(2.90)$ & $15.88(3.18)$ & 0.004 \\
Tinetti Balance Test & $7.03(2.85)$ & $8.53(3.35)$ & 0.000 \\
SCEF & & & \\
$\quad$ Walking & $2.94(0.85)$ & $3.40(0.70)$ & 0.000 \\
$\quad$ Transferring & $3.39(0.89)$ & $3.63(0.76)$ & 0.012 \\
$\quad$ Turning & $3.77(0.56)$ & $3.80(0.51)$ & $\mathrm{ns}$ \\
$\quad$ Lifting & $3.55(0.65)$ & $3.70(0.53)$ & 0.021 \\
$\quad$ Using the toilet & $3.57(0.80)$ & $3.65(0.75)$ & $\mathrm{ns}$ \\
$\quad$ Feeding & $3.83(0.40)$ & $3.88(0.38)$ & $\mathrm{ns}$ \\
$\quad$ Getting ready & $3.12(0.80)$ & $3.13(0.84)$ & $\mathrm{ns}$ \\
$\quad$ Dressing & $3.06(1.07)$ & $3.18(1.06)$ & $\mathrm{ns}$ \\
$\quad$ Bathing & $1.89(1.15)$ & $2.13(1.27)$ & $\mathrm{ns}$ \\
\hline
\end{tabular}

Data are presented as the mean (SD). MMSE, Mini Mental State Examination; SCEF, SelfCare Evaluation Form.
Table 2. Odds ratio risk factors associated with falls tested in older adults living in nursing homes $(n=325)$

\begin{tabular}{lll}
\hline & OR & $95 \% \mathrm{Cl}$ \\
\hline Gender & 1.39 & $\mathrm{~ns}$ \\
Resorting to the ES in the last year & 2.72 & $1.71-4.33$ \\
Polypharmacy ( $\geq 5$ types of medicine) & 1.74 & $1.09-2.78$ \\
Overactive bladder & 1.90 & $1.14-3.19$ \\
Functional dyspnea & 1.87 & $1.19-2.93$ \\
Paresthesia & 1.73 & $1.09-2.74$ \\
Difficulty sleeping & 1.72 & $1.07-2.75$ \\
SCHDE & & \\
$\quad$ Formally guided & 0.70 & $\mathrm{~ns}$ \\
$\quad$ Responsible & 1.89 & $1.20-2.99$ \\
$\quad$ Independent & 2.36 & $1.49-3.74$ \\
$\quad$ Abandoned & 1.59 & $1.01-2.51$ \\
\hline
\end{tabular}

ES, emergency services; SCHDE, self-care of home dwelling elderly.

falling from the bed $(7.8 \% ; n=11)$, and with $4.9 \%$ of older adults $(n=7)$ falling on the stairs.

The analysis of the continuous variables considered for the older adults who did or did not suffer a fall is displayed in detail in Table 1. The older adults who fell had shown less autonomy in four of the SCEF domains (walking, transferring, lifting, and recreational activities), had more limitations related to carrying out the activities of daily living (Barthel index), and a more compromised static balance (Tinetti Balance Test). Neither age nor the length of time living in the nursing home, and not even the mental state (MMSE), presented significant results in the comparison between both groups. This analysis resulted from the comparison of the significant differences in the averages for the aforementioned variables, accounting for older adults who fell and those who did not, with a focus on the first group (Table 1).

The analysis of a set of possible risk factors associated with falls was carried out with support from the literature by an odds ratio analysis (Table 2). Of the clinical variables studied, only those that showed a statistical association with the risk of falls are reported. For this analysis, different dichotomised variables were assessed, namely gender, an overactive bladder, functional dyspnea, paresthesia, sleeping problems, polypharmacy (cut-off 5 or more types of medicines), and resorting to the emergency services in the last year. In addition, the self-care profiles were tested to verify the hypothesis considered. The odds ratio analysis indicated that only gender and the formally guided profile were not probable risks of fall $(p \geq 0.05)$.

Due to the multicollinearity with the Tinetti Balance Test and different domains of the SCEF, the latter were not included in the predictive model. The 10 variables that were significant at the first preliminary analyses (Table 1,2 ) were used to build the estimation model of the risk factors that best explain the falls. The analysis was performed in four steps until the final model was obtained, presenting a significant coefficient in each step. The Hosmer-Lemeshow test values suggested a good ad- 
Table 3. Binary logistic regression analysis using the 10 significant variables found with the odds ratio

\begin{tabular}{|c|c|c|c|c|c|c|c|}
\hline & & \multirow[t]{2}{*}{ B } & \multirow[t]{2}{*}{ Wald } & \multirow[t]{2}{*}{ Sig. } & \multirow[t]{2}{*}{$\operatorname{Exp}(B)$} & \multicolumn{2}{|c|}{$95 \%$ Cl for $\operatorname{Exp}(B)$} \\
\hline & & & & & & lower & upper \\
\hline Step 1 & $\begin{array}{l}\text { Tinetti Balance Test } \\
\text { Constant }\end{array}$ & $\begin{array}{l}-0.18 \\
1.17\end{array}$ & $\begin{array}{l}17.92 \\
11.53\end{array}$ & $\begin{array}{l}0.000 \\
0.001\end{array}$ & $\begin{array}{l}0.84 \\
3.21\end{array}$ & 0.77 & 0.91 \\
\hline Step 2 & $\begin{array}{l}\text { Tinetti Balance Test } \\
\text { RES } \\
\text { Constant }\end{array}$ & $\begin{array}{l}-0.18 \\
0.91 \\
0.60\end{array}$ & $\begin{array}{l}16.39 \\
12.95 \\
2.54\end{array}$ & $\begin{array}{l}0.000 \\
0.000 \\
0.111\end{array}$ & $\begin{array}{l}0.84 \\
2.47 \\
1.83\end{array}$ & $\begin{array}{l}0.77 \\
1.51\end{array}$ & $\begin{array}{l}0.91 \\
4.05\end{array}$ \\
\hline Step 3 & $\begin{array}{l}\text { Tinetti Balance Test } \\
\text { RES } \\
\text { Independent self-care profile } \\
\text { Constant }\end{array}$ & $\begin{array}{l}-0.16 \\
0.88 \\
0.70 \\
0.08\end{array}$ & $\begin{array}{l}13.71 \\
11.84 \\
7.14 \\
0.03\end{array}$ & $\begin{array}{l}0.000 \\
0.001 \\
0.008 \\
0.854\end{array}$ & $\begin{array}{l}0.85 \\
2.40 \\
2.01 \\
1.08\end{array}$ & $\begin{array}{l}0.78 \\
1.46 \\
1.21\end{array}$ & $\begin{array}{l}0.93 \\
3.96 \\
3.36\end{array}$ \\
\hline Step 4 & $\begin{array}{l}\text { Tinetti Balance Test } \\
\text { RES } \\
\text { Independent self-care profile } \\
\text { Polypharmacy } \\
\text { Constant }\end{array}$ & $\begin{array}{l}-0.16 \\
0.86 \\
0.68 \\
0.52 \\
-0.25\end{array}$ & $\begin{array}{l}13.16 \\
11.15 \\
6.60 \\
3.84 \\
0.28\end{array}$ & $\begin{array}{l}0.000 \\
0.001 \\
0.010 \\
0.050 \\
0.594\end{array}$ & $\begin{array}{l}0.85 \\
2.36 \\
1.97 \\
1.69 \\
0.78\end{array}$ & $\begin{array}{l}0.78 \\
1.43 \\
1.17 \\
1.00\end{array}$ & $\begin{array}{l}0.93 \\
3.90 \\
3.29 \\
2.84\end{array}$ \\
\hline
\end{tabular}

RES, having resorted to emergency services.

justment to the model since non-significant $\chi^{2}$ values were found.

The Wald $\chi^{2}$ statistic, which refers to the significance of the constant variable was $3.86(p=0.04)$, showing that the constant variable of the regression model is significant and contributes to the prediction of falling risk for older adults. The final model presents four variables significantly related to falls within this sample. The one with the highest predictive power for falls was the static balance (Wald $\chi^{2}=17.92$ ), followed by having resorted to the emergency services (Wald $\chi^{2}=12.95$ ). The third variable to explain the model was the presence of an internal functioning associated with the independent self-care profile (Wald $\chi^{2}=7.14$ ) and the last risk entering the model was polypharmacy (Wald $\chi^{2}=3.84$ ). This result showed polypharmacy to be a marginally significant predictor $(p=$ $0.05)$. In summary, a higher static balance shows a protective effect against falls in older adults, while having resorted to the emergency services, having an independent self-care profile, and polypharmacy are independent risk factors for falls (Table 3).

The model's discriminative power was assessed considering the most important predictors by analysing the AUC. An optimal cut-off value for adequate sensitivity and specificity was also implemented based on the Youden index [44]. The final risk score was found to be an acceptable predictor of falls through the ROC curve analysis
(AUC $=0.71,95 \% \mathrm{CI}=0.64-0.76$ ), as can be seen in Figure 1 , confirming that fall prediction using this model was $71 \%$ accurate. The model showed a sensitivity of $51 \%$, a specificity of $73.5 \%$, a false positive rate of $26.5 \%$, a false negative rate of $49.3 \%$, a positive predictive value positive of $59.3 \%$, and a negative predictive value of $33.8 \%$.

It was decided at this point to calculate the cut-off point for the Tinetti Balance Test that represents the value at which older adults are at a great risk of falls. For this analysis, the value of the Tinetti Balance Test was inverted. The AUC $=0.62,95 \% \mathrm{CI}=0.56-0.68$, and the cut-off point with the best Youden index for these older adults living in nursing homes was 9.5.

\section{Discussion}

The results show that a high number of participants suffered from a fall, reflecting the size of this problem in terms of public health care within the context of nursing homes. The scientific literature has corroborated the high prevalence of falls within the different types of structures designed to care for older adults $[45,46]$. About one-third of all the older adults studied who fell in the last year experienced recurring falls, and a great proportion of those who fell suffered some type of lesion. These findings reveal a pattern of great frailty in institutionalised older 


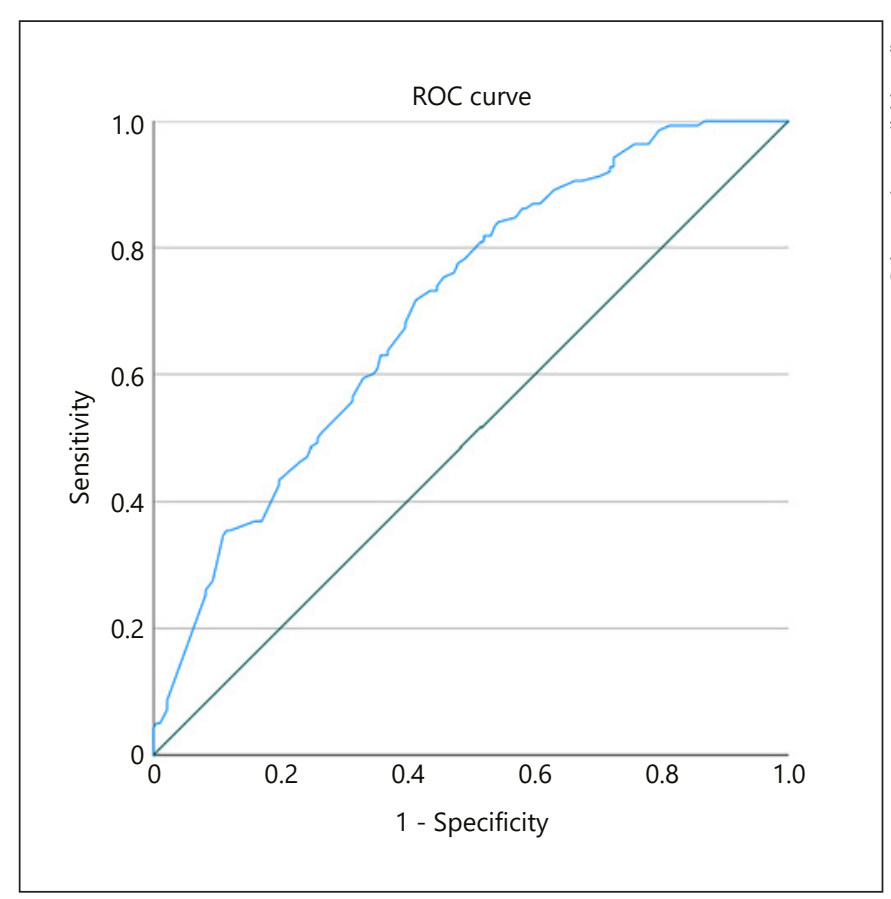

Fig. 1. ROC curve of the fall prediction model.

adults, considering that these falls can often result in a loss of independence and even death $[4,8,46]$. Moreover, the results are more worrisome than those found in other studies carried out in similar contexts $[15,16,47]$. The differences may be associated with the methodology used in the studies, i.e., resorting to younger participants, less severe health conditions, as well as different patterns of registering falls.

The main goal of this study was to find variables that explain falls in independent older adults with a slight/ moderate loss of independence, living in nursing homes. No differences were found between cases and controls in terms of sex, age, mental state, and the time of institutionalisation. These results are probably related to the sample, as participants had a poor health status and it was mainly composed of females. Usually, older adults enter a nursing home when they have lost independence and autonomy, conditions associated with cognitive and physical impairment. All older adults were institutionalised for more than 1 year (inclusion criteria), which allowed the residents to know the devices, the equipment, and the architectural barriers of the nursing homes. Concerning the SCEF domains, only four were relevant to the risk of falling: walking, transferring, lifting, and recreational activities. These factors are related to muscle strength, gait, and balance. These conditions explained the performance of those ADL. Older adults resort to emergency services for other causes than falls, because their state of health is somewhat deteriorated which therefore increases the risk of falling [28]. However, the link between resorting more to the emergency services and the outcome of falls can be seen as an indicator of frailty, because it is a fall risk factor, as several studies have pointed out $[8,48,49]$. Polypharmacy, dyspnea, overactive bladder, and paresthesia were unsurprisingly found to be risk factors for falls $[4,8$, 20-24, 29, 30].

The hypothesis formulated about the contribution of the four self-care profiles [32] as risk factors for falls was partially confirmed. Results suggested that, except for the formally guided profile, the other three profiles were fall risk factors, which is a new discovery in the field of fall risk factors for older adults. Responsible and abandoned self-care profiles have a lower risk when compared with an independent profile. People with an independent selfcare profile value autonomy and take unnecessary risks, which can result in falls $[32,41]$. In fact, this profile has a higher chance of falling than the others. Falls in the other profiles are probably more related to physical impairments than personality characteristics. All the factors identified as fall risks for the institutionalised older adults, except the self-care profiles, are widely known and published $[4,6-8,10,22-24,26,30,45,46,50-53]$.

The second main objective of the present study was to build a predictive model that would find the best predictors of falls among older adults living in nursing homes. According to the binary logistic regression model, the main variables associated with falls were static balance, resorting more to the emergency services, an independent self-care profile, and polypharmacy. In this study, a static balance was shown to be the best predictive fall risk factor for the older adults living in nursing homes, in accordance with scientific literature $[4,8,30,50,53]$. Therefore, it is suggested, that having multidisciplinary clinical teams, trained to assess and in applying specific techniques for working on balance, maybe one way to achieve a better quality of physical life. In nursing homes, the organisation often includes some type of restriction in the activities of the older adults, with the hope of preventing accidents. Older adults who are cognitively impaired, have limitations in terms of their gait, balance, or suffer from a fear of falling are encouraged to be careful and not to move without supervision. On the other hand, the ratio of the older adults per staff member does not contribute to motor stimulation or physical activity that promotes their functional capacity. In addition, several of the older 
people and their families feel they do not have to carry out any tasks, because they pay for their stay in the nursing homes (i.e., make the bed, tidy their clothes, dust their room, participate in light kitchen tasks, set the table), preferring to have someone else do it altogether. Working with older adults and their families to face the clinical fact that several tasks can be therapeutic techniques and not a way to extort families, is another way to intervene. Seminars and discussions with staff, older adults, and their families could be the first solution to this problem.

Polypharmacy has been one of the predictors highlighted in the analyses of explanatory models of falls $[4,8$, $30,50,53]$. Although polypharmacy was a significant risk factor in our model as well, it was not possible to evaluate the effect of specific drugs with very strong evidence as fall risk factors, such as psychotropic drugs [30], because this information was not collected. As a variable included in the predictive model, though polypharmacy shows a significant marginal value, it should still be taken into consideration with this population group. Considering that there is a pattern of polypharmacy, i.e., to have five or more types of medicine is the cut-off point for having a risk of falling, reviewing the medication should be a regular practice in nursing homes. Also, some medicines can be a moderator of the risk, for example when the nursing home teams chose, whenever possible, to lower the doses of diazepam, replacing them with modes of intervention more associated with the cognitive or motor significant activities, interventions associated with greater reasonable physical exercise or even, in the case of anxiety or depression, of considering a psychological intervention. The independent self-care profile characterises people that value autonomy, who believe they have the internal resources to make a rational decision, acting according to their convictions, often refusing advice or guidance from professionals, especially when these do not correspond to their own beliefs or personal values. They tend to be very decisive people, who do not always make the best choices, though they believe they are acting correctly. When they notice something is not well, they tend not to look for help, trying to solve their problems themselves, often through trial and error. They also tend to consider themselves healthier than they are. The autonomy without the notion that the older age brings boundaries seems to promote higher risk of having a fall. This variable has not been previously studied as a fall predictor; therefore, this study has provided an important contribution to help clarify its role.

Datta et al. [54] stated that the fall risk factors for older adults living in nursing homes seem to be different than those identified for the older adults living within the community. For the most part, their health condition tends to be weaker and less functional.

In the Portuguese context, a significant number of residential facilities for older adults are located in inadequate buildings, often designed for other purposes, with several architectural barriers, which result in high environmental risk factors [54]. The evidence shows that the falls among institutionalised older adults result from a dynamic and complex interaction between multiple variables (intrinsic and extrinsic), where environmental factors have a significant relationship with the falls $[45,55]$. One of the limitations of this study was the lack of evaluation of the environmental factors related to the nursing homes in the study, as it is suggested that they may have had a strong influence on the occurrence of falls. On the other hand, it should be a key subject in future studies which intend to improve the set of predictors of falling in these kinds of facilities.

By analysing the ROC curve, the predictive model, which was calculated through a binary logistic regression, correctly classified $71 \%$ of the falls. While the specificity obtained an acceptable value, the sensitivity is still low (51\%). However, other predictive factors for falls showed similar results $[24,56]$ even showing lower specificity values than those obtained in the present study [54].

Although it was not an initial objective, the cut-off value of the Tinetti Balance Test was computed to find the value to which older adults are at a great risk of falls. The value with the best discrimination was 9.5. This could be used in the assessment of older adults to monitor more accurately and quickly the risk of falls associated with static balance, and is another added value of this study.

Older adults require attention and monitoring for their self-care activities to be preserved and stimulated. Therefore, monitoring is essential for psychomotor and emotional stimulation. A basic guideline is to promote physical activity of moderate intensity for at least $150 \mathrm{~min}$ a week, plus muscle strengthening, in addition to balance training 3 or more days per week for older adults at risk of falling. This must be ensured in accordance with what the person's abilities are and what the conditions allow $[8$, 55].

The literature has suggested that falls occur more frequently among nursing home older adults than among those who are living in the community $[15,16,26,57]$. Falls can cause distress, pain, injury, loss of confidence, loss of independence, and mortality. Nevertheless, some falls that occur in nursing homes could be avoided. The number of falls in care facilities is a real problem that re- 
quires more attention and more controlled measures. Some of these measures might include the selection of safer materials and equipment and monitoring the risk of falls, taking into consideration the predictive variables. In addition, individuals with severe cognitive and physical impairment cannot be left alone and require closer monitoring than that usually provided in Portuguese institutions. Implementing physical activity can help optimise health and prevent falls, as well as promote the social participation and mental health of older adults. Reducing the number of falls could reduce social pressures at the institution and improve the quality of life of older adults. In addition, the development of more adaptive skills according to the self-care profiles is important from a proactive perspective. Therefore, the development of these skills should be promoted continuously to prevent the establishment of less adaptive self-care profiles before reaching older adulthood.

\section{Conclusion}

The present study confirmed that the risk of falls in older adults living in nursing homes is multifactorial in nature, replicating most of the results that had been previously established by the scientific community, while at the same time highlighting the need to enhance and motivate young researchers to try to find new risk factors to improve the living conditions of older adults in these contexts. That was the case for integrating the self-care profiles by Backman and Hentinen [32] in the present study, suggesting the need for future replicas to be studied in more depth. Nevertheless, it is a novelty according to the reviewed studies used in the present research. The calculation of a cut-off point allowing to quickly integrate older adults with the same characteristics as the ones studied here is also considered an added value that should be implanted in other studies, even transcultural ones.
The tested risk factors that proved to be significant for falling were static balance, resorting to the emergency services in the last year, polypharmacy, overactive bladder, dyspnea, paresthesia, difficulty sleeping, and the self-care profiles, except for the formally guided profile. Although also multifactorial, the model presented static balance, resorting to the emergency services in the last year, polypharmacy and an independent self-care profile as the fall predictors to first take into account in terms of possible interventions.

\section{Statement of Ethics}

This research was in accordance with the Ethical Committee of the World Medical Association Declaration of Helsinki. Ethical principles were followed with the right to anonymity, privacy, and data confidentiality (when collecting and treating the data). The free and informed consent from the participants was gathered according to the ethical principles of research in human sciences. The ethics commission of Abel Salazar Institute of Biomedical Sciences of the University of Porto, under registration number $166 / 2016$, approved this research project.

\section{Conflict of Interest Statement}

The authors have no conflicts of interest to declare.

\section{Funding Sources}

No funding was received for this work.

\section{Author Contributions}

All authors wrote the paper. C.I. conducted the old adult assessment and records; T.M. performed the data analysis. All authors reviewed and contributed with their knowledge to the writing of the paper.

\section{References}

1 US Centers for Disease Control and Prevention. Falls in nursing homes [Internet]. Atlanta: US Centers for Disease Control and Prevention; 2013 [cited 16 Set 2021]. Available from: http://www.cdc.gov/HomeandRecreationalSafety/Falls/adultfalls.html.

2 Ingelfinger FJ. Editorial: National Center for Health Statistics. N Engl J Med. 1973 Nov;289(21):1142-3.
3 Teixeira DK, Andrade LM, Santos JL, Caires ES. Falls among the elderly: environmental limitations and functional losses. Rev Bras Geriatr Gerontol. 2019;22. doi: https://doi. org/10.1590/1981-22562019022.180229.

4 Damián J, Pastor-Barriuso R, ValderramaGama E, de Pedro-Cuesta J. Factors associated with falls among older adults living in institutions. BMC Geriatr. 2013 Jan;13(1):6.
5 Ferreira OG, Maciel SC, Costa SM, Silva AO, Moreira MA. Active aging and its relationship to functional independence. Texto Context Enferm. 2012;21:513-8. doi: https://doi. org/10.1590/S0104-07072012000300004.

6 Xue QL. The frailty syndrome: definition and natural history. Clin Geriatr Med. 2011 Feb;27(1):1-15. 
7 Lan X, Li H, Wang Z, Chen Y. Frailty as a predictor of future falls in hospitalized patients: A systematic review and meta-analysis. Geriatr Nurs. 2020 Mar - Apr;41(2):69-74.

8 Enderlin C, Rooker J, Ball S, Hippensteel D, Alderman J, Fisher SJ, et al. Summary of factors contributing to falls in older adults and nursing implications. Geriatr Nurs. 2015 SepOct;36(5):397-406.

9 World Health Organization. WHO global report on falls prevention in older age [Internet]. Geneva: WHO; 2004 [cited 16 Set 2021]. https://doi.org/10.1353/jowh.2004.0010.

10 Deandrea S, Bravi F, Turati F, Lucenteforte E, La Vecchia C, Negri E. Risk factors for falls in older people in nursing homes and hospitals. A systematic review and meta-analysis. Arch GerontolGeriatr.2013May-Jun;56(3):407-15.

11 Lojudice DC, Laprega MR, Aparecida R, Rodrigues P, Luis A, Júnior R. Falls of institutionalized elderly: occurrence and associated factors. Rev Bras Geriatr Gerontol. 2010;13:403-12.

12 Rodrigues RA, Fabricio-Wehbe SC, Diniz MA, Fhon JR, Silva AF. Falls in older adults living at home and their association with daily living activities. Rev Enferm. 2015;23:58995.

13 Choi H, Hayward RA, Langa KM. Fall associated difficulty with activities of daily living (ADL) in functionally independent older adults aged 65 to 69 in the United States: a cohort study. J Am Geriatr Soc. 2013;61:1-7.

14 Ferreira DC, Yoshitome AY. Prevalence and features of falls of institutionalized elders. Rev Bras Enferm. 2010;63(6):991-7. Portuguese.

15 Castaldo A, Giordano A, Antonelli Incalzi R, Lusignani M. Risk factors associated with accidental falls among Italian nursing home residents: A longitudinal study (FRAILS). Geriatr Nurs. 2020 Mar - Apr;41(2):75-80.

16 Sharifi F, Fakhrzadeh H, Memari A, Najafi B, Nazari N, Khoee MA, et al. Predicting risk of the fall among aged adult residents of a nursing home. Arch Gerontol Geriatr. 2015 SepOct;61(2):124-30.

17 Lindholm B, Eek F, Skogar Ö, Hansson EE. Dyskinesia and FAB score predict future falling in Parkinson's disease. Acta Neurol Scand. 2019 Jun;139(6):512-8.

18 El Miedany Y, El Gaafary M, Toth M, Palmer D, Ahmed I. Falls risk assessment score (FRAS): time to rethink. J Clin Gerontol Geriatr. 2011;2(1):21-6.

19 Yoo SH, Kim SR, Shin YS. A prediction model of falls for patients with neurological disorder in acute care hospital. J Neurol Sci. 2015 Sep;356(1-2):113-7.

20 Thurman DJ, Stevens JA, Rao JK; Quality Standards Subcommittee of the American Academy of Neurology. Practice parameter: Assessing patients in a neurology practice for risk of falls (an evidence-based review): report of the Quality Standards Subcommittee of the American Academy of Neurology. Neurology. 2008 Feb;70(6):473-9.
21 Strait S, Medcalf P. Peripheral neuropathy in older people. Geriatr Med J. 2012;42:47-52.

22 Szabo SM, Gooch KL, Walker DR, Johnston $\mathrm{KM}$, Wagg AS. The association between overactive bladder and falls and fractures: a systematic review. Adv Ther. 2018 Nov;35(11):1831-41.

23 Severo IM, Kuchenbecker R, Vieira DF, Pinto LR, Hervé ME, Lucena AF, et al. A predictive model for fall risk in hospitalized adults: A case-control study. J Adv Nurs. 2019 Mar;75(3):563-72.

24 Homer ML, Palmer NP, Fox KP, Armstrong J, Mandl KD. Predicting falls in people aged 65 years and older from insurance claims. Am J Med. 2017 Jun;130(6):744.e17-23.

25 Stone KL, Ancoli-Israel S, Blackwell T, Ensrud KE, Cauley JA, Redline S, et al. Actigraphy-measured sleep characteristics and risk of falls in older women. Arch Intern Med. 2008 Sep;168(16):1768-75.

26 Marier A, Olsho LE, Rhodes W, Spector WD. Improving prediction of fall risk among nursing home residents using electronic medical records. J Am Med Inform Assoc. 2016 Mar;23(2):276-82.

27 World Health Organization. Health topics: falls 2018 [Internet]. Geneva: WHO; 2018 [cited 16 Set 2021]. Available from: https:// www.who.int/news-room/fact-sheets/detail/ falls.

28 Min L, Tinetti M, Langa KM, Ha J, Alexander N, Hoffman GJ. Measurement of fall injury with health care system data and assessment of inclusiveness and validity of measurement models. JAMA Netw Open. 2019 Aug;2(8):e199679.

29 Miranda DP, Santos TD, Santo FH, Chibante CL, Barreto EA. Quedas em idosos em ambiente domiciliar: uma revisão integrativa. REAID [Internet]. 2019. Available from: https://www.revistaenfermagematual.com. br/index.php/revista/article/view/560.

30 Smith MI, De Lusignan S, Mullett D, Correa A, Tickner J, Jones S. Predicting falls and when to intervene in older people: a multilevel logistical regression model and cost analysis. Nutrition. 1999;15:116-22.

31 Miner B, Tinetti ME, Van Ness PH, Han L, Leo-Summers L, Newman AB, et al. Dyspnea in community-dwelling older persons: a multifactorial geriatric health condition. J Am Geriatr Soc. 2016 Oct;64(10):2042-50.

32 Backman K, Hentinen M. Model for the selfcare of home-dwelling elderly. J Adv Nurs. 1999 Sep;30(3):564-72.

33 Cameron ID, Dyer SM, Panagoda CE, Murray GR, Hill KD, Cumming RG, et al. Interventions for preventing falls in older people in care facilities and hospitals. Cochrane Database Syst Rev. 2018 Sep;9:CD005465. https:// doi.org/10.1002/14651858.CD005465.pub4.

34 Sims JM. A brief review of the Belmont report. Dimens Crit Care Nurs. 2010 JulAug;29(4):173-4.
35 Araújo F, Oliveira A, Pinto C, Ribeiro J. Validação do Índice de Barthel numa amostra de idosos não institucionalizados. Rev Port Saude Publica. 2007;25:59-66.

36 Guerreiro M, Silva AP, Botelho MA, Leitão O, Castro-Caldas A, Garcia C. Adaptação a população portuguesa da tradução do Mini Mental State Examination (MMSE). Rev Port Neurol. 1994;1:9-10

37 Morgado J, Rocha CS, Maruta C, Guerreiro M, Martins IP. Novos valores normativos do Mini-Mental State Examination. Sinapse. 2009;2:10-6.

38 Parente P, Costa A, Pereira S, Machado P, Martins T, Pereira F, et al. Self-Care Dependency Evaluation Form: psychometric properties of the revised version with 27 items. Scand J Caring Sci. 2021. doi: 10.1111/ scs. 12966.

39 International Council of Nurses. Classificação Internacional para a Prática de Enfermagem: CIPE: versão 1.0. Lisbon: Ordem dos Enfermeiros; 2006.

40 Moorhead S, Johnson M, Maas M. Nursing Outcomes Classification (NOC). Porto Alegre: Artmed; 2008.

41 Imaginário C, Rocha M, Machado P, Antunes C, Martins T. Self-care profiles of the elderly institutionalized in elderly care centres. Arch Gerontol Geriatr. 2018;78:89-95.

42 Petiz EM. A actividade física, equilíbrio e quedas: um estudo em idosos institucionalizados. Porto: University of Porto; 2002.

43 Unal I. Defining an optimal cut-point value in ROC analysis: an alternative approach. Comput Math Methods Med. 2017;2017:3762651.

44 Hajian-Tilaki K. Receiver operating characteristic (ROC) curve analysis for medical diagnostic test evaluation. Caspian J Intern Med. 2013;4(2):627-35.

45 Zhang L, Zeng Y, Weng C, Yan J, Fang Y. Epidemiological characteristics and factors influencing falls among elderly adults in longterm care facilities in Xiamen, China. Medicine. 2019 Feb;98(8):e14375.

46 Carryer J, Weststrate J, Yeung P, Rodgers V, Towers A, Jones M. Prevalence of key care indicators of pressure injuries, incontinence, malnutrition, and falls among older adults living in nursing homes in New Zealand. Res Nurs Health. 2017 Dec;40(6):555-63.

47 Del Duca GF, Antes DL, Hallal PC. Falls and fractures among older adults living in longterm care. Rev Bras Epidemiol. 2013 Mar;16(1):68-76. Portuguese.

48 UK National Institute for Health and Care Excellence. Falls and fragility fractures [Internet]. London: National Institute for Health and Care Excellence; 2018 [cited 16 Set 2021]. Available from: https://www.nice.org.uk/Media/Default/About/what-we-do/Into-practice/measuring-uptake/NICE-Impact-fallsand-fragility-fractures.pdf.

49 Duarte GP, Santos JL, Lebrão ML, Duarte YA Relationship of falls among the elderly and frailty components. Rev Bras Epidemiol. 2019 Feb;21(21 Suppl 02):e180017. 
50 Abreu HC, Reiners AA, Azevedo RC, Silva $\mathrm{AM}$, Abreu DR, Oliveira AD. Incidence and predicting factors of falls of older inpatients. Rev Saude Publica. 2015;49:37. doi: https:// doi.org/10.1590/S0034-8910.2015049005549.

51 Ming Y, Zecevic A. Medications \& polypharmacy influence on recurrent fallers in community: a systematic review. Can Geriatr J. 2018 Mar;21(1):14-25.

52 Álvarez Barbosa F, Del Pozo-Cruz B, Del Pozo-Cruz J, Alfonso-Rosa RM, Sañudo Corrales B, Rogers ME. Factors associated with the risk of falls of nursing home residents aged 80 or older. Rehabil Nurs. 2016 JanFeb;41(1):16-25.
53 Dhargave P, Sendhilkumar R. Prevalence of risk factors for falls among elderly people living in long-term care homes. J Clin Gerontol Geriatr. 2016;7(3):99-103.

54 Datta A, Datta R, Elkins J. What factors predict falls in older adults living in nursing homes: a pilot study. J Funct Morphol Kinesiol. 2018 Dec;4(1):e3.
55 Resnick B. Falls: do we know anything more than we did 40 years ago? Geriatr Nurs. 2020 Mar - Apr;41(2):67-8.

56 Neumann L, Hoffmann VS, Golgert S, Hasford J, Von Renteln-Kruse W. In-hospital fallrisk screening in 4,735 geriatric patients from the LUCAS project. J Nutr Health Aging. 2013 Mar;17(3):264-9.

57 Cameron EJ, Bowles SK, Marshall EG, Andrew MK. Falls and long-term care: a report from the care by design observational cohort study. BMC Fam Pract. 2018 May;19(1):73. 